\title{
High-Yield Synthesis of Stoichiometric Boron Nitride Nanostructures
}

\author{
José E. Nocua, ${ }^{1,2}$ Fabrice Piazza, ${ }^{3}$ Brad R. Weiner, ${ }^{1,4}$ and Gerardo Morell ${ }^{1,2}$ \\ ${ }^{1}$ Institute for Functional Nanomaterials, University of Puerto Rico, San Juan, PR 00931, USA \\ ${ }^{2}$ Department of Physics, University of Puerto Rico, Río Piedras Campus, San Juan, PR 00931, USA \\ ${ }^{3}$ Pontificia Universidad Católica Madre y Maestra, P.O. Box 2748, Santo Domingo, Dominican Republic \\ ${ }^{4}$ Department of Chemistry, University of Puerto Rico, Río Piedras Campus, San Juan, PR 00931, USA
}

Correspondence should be addressed to Gerardo Morell, gmorell@gmail.com

Received 11 June 2009; Accepted 5 October 2009

Recommended by Songwei Lu

Boron nitride (BN) nanostructures are structural analogues of carbon nanostructures but have completely different bonding character and structural defects. They are chemically inert, electrically insulating, and potentially important in mechanical applications that include the strengthening of light structural materials. These applications require the reliable production of bulk amounts of pure $\mathrm{BN}$ nanostructures in order to be able to reinforce large quantities of structural materials, hence the need for the development of high-yield synthesis methods of pure $\mathrm{BN}$ nanostructures. Using borazine $\left(\mathrm{B}_{3} \mathrm{~N}_{3} \mathrm{H}_{6}\right)$ as chemical precursor and the hot-filament chemical vapor deposition (HFCVD) technique, pure BN nanostructures with cross-sectional sizes ranging between 20 and $50 \mathrm{~nm}$ were obtained, including nanoparticles and nanofibers. Their crystalline structure was characterized by (XRD), their morphology and nanostructure was examined by (SEM) and (TEM), while their chemical composition was studied by (EDS), (FTIR), (EELS), and (XPS). Taken altogether, the results indicate that all the material obtained is stoichiometric nanostructured $\mathrm{BN}$ with hexagonal and rhombohedral crystalline structure.

Copyright (C) 2009 José E. Nocua et al. This is an open access article distributed under the Creative Commons Attribution License, which permits unrestricted use, distribution, and reproduction in any medium, provided the original work is properly cited.

\section{Introduction}

BN crystallizes in various allotropic forms that are analogous to carbon allotropes (graphite, diamond, fullerene) in terms of their corresponding structures, although they have different bonding character and physical properties $[1,2]$. The cubic and hexagonal phases of $\mathrm{BN}$ show mechanical and thermal properties that are very similar to those of diamond and graphite, respectively. However, in contrast to carbon nanofibers and carbon nanotubes (CNTs), BN nanostructures are electrically insulating, with an energy gap of $\sim 5.5 \mathrm{eV}[3-5]$ and resistant to oxidation up to $800^{\circ} \mathrm{C}[6,7]$. These characteristics make $\mathrm{BN}$ nanostructures more appropriate than carbon nanostructures for reinforcing industrial ceramics, such as alumina $\left(\mathrm{Al}_{2} \mathrm{O}_{3}\right)$ and silicon nitride ( $\mathrm{SiN}$ ), to improve their tolerance to abrupt thermal fluctuations $[8,9]$.

The BN nanostructures are not only structurally similar to carbon nanostructures [10], but the methods used to synthesize them generally are modifications of those used to synthesize CNTs. For example, using nickel boride particles as catalytic agent, multiwalled BN nanotubes and the HFCVD technique were fabricated [11]. This and many other efforts to synthesize BN nanomaterials, including nanofibers [12], nanotubes [13], nanocapsules [14], nanowires [15], nanoparticles [16], and BN films [17], have resulted in low yields and significant amounts of codeposited impurities. Moreover, reports on the bulk synthesis methods of $B N$ nanotubes $[18,19]$ exemplify the issue of $B$ segregation and $\mathrm{N}$ deficiency due to nitrogen evolution during the synthesis of BN nanostructures, which are major drawbacks that affect all synthesis methods reported to date.

$\mathrm{BN}$ nanostructures can be manufactured using different boron and nitrogen compounds as precursors; we have chosen borazine in this study. This inorganic compound offers the advantages of not being corrosive and of being much less toxic than other candidates, such as $\mathrm{B}_{2} \mathrm{H}_{6}, \mathrm{BCl}_{3}$, and $\mathrm{NH}_{3}$, which involve highly complex reactions that cause the resulting films to depend strongly on the experimental parameters [20]. In addition, borazine is isostructural and 

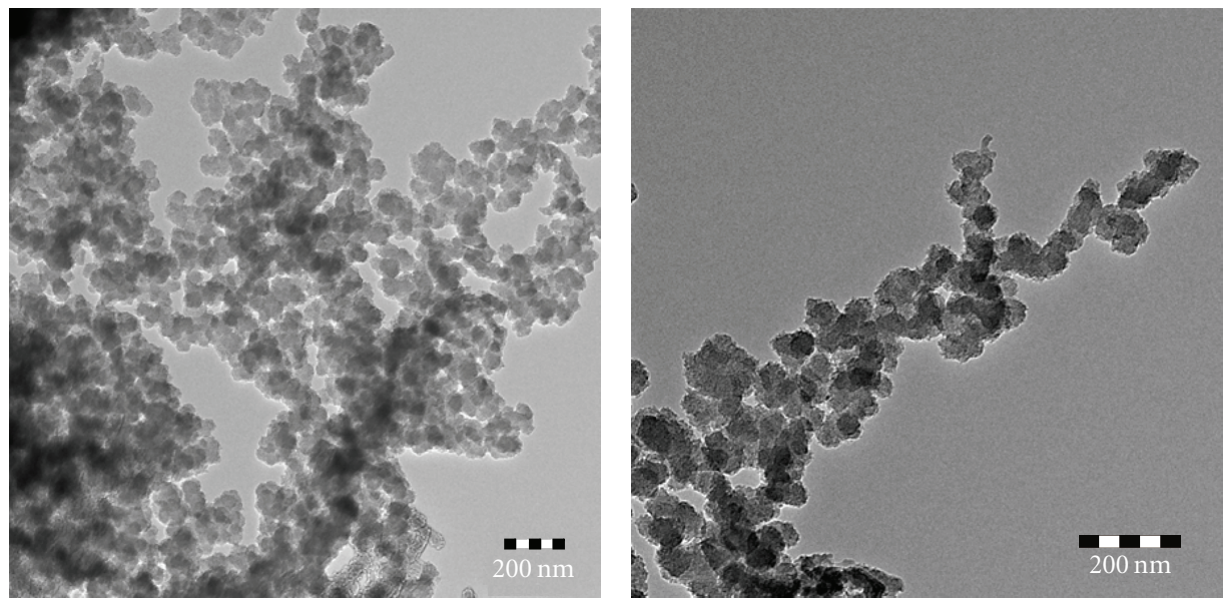

FIGURE 1: TEM images showing the BN nanostructures, including quasispherical nanoparticles and nanofibers.

isoelectronic with benzene and has high vapor pressure, the exact $1: 1$ proportion of $\mathrm{B}: \mathrm{N}$, and three $\mathrm{B}-\mathrm{N}$ bonds, all of which favor the stoichiometric synthesis of BN nanostructures with only hydrogen as a potential impurity [21]. The stoichiometric advantage of borazine can be however lost if high-energy synthesis techniques are employed, which break the borazine molecule in many pieces, promote the evolution of nitrogen gas, and scramble the stoichiometry of the solid state product.

In this article, we report the high-yield synthesis of stoichiometric BN nanostructures by the HFCVD technique using borazine as precursor, without any type of catalytic agent, and no measurable elemental segregation of $\mathrm{B}$ or $\mathrm{N}$. This technique provides precise temperature and pressure control, which is essential to obtain the optimum yield and negligible amounts of unintentional impurities or nonstoichiometric B-N compounds.

\section{Experimental Methodology}

The HFCVD reactor consists of a stainless steel chamber, $27 \mathrm{~cm}$ in diameter and $27 \mathrm{~cm}$ in height. At the center of the chamber, there is a substrate heater, $5 \mathrm{~cm}$ in diameter, placed under the filament. The filament consists of a rhenium wire, $8 \mathrm{~cm}$ in length and $0.5 \mathrm{~mm}$ in diameter, coiled into a $5 \mathrm{~mm}$ diameter cylinder. A copper substrate, $15.0 \mathrm{~mm}$ in diameter and $1.0 \mathrm{~mm}$ in thickness, which had been previously cleaned with methanol in ultrasound for 5 minutes, was placed on the heater, and the height of the filament was adjusted to $8.0 \mathrm{~mm}$ above the copper substrate.

Using a mechanical pump, a baseline vacuum of $0.03 \mathrm{~Pa}$ $\left(\sim 2 \times 10^{-4}\right.$ Torr $)$ was achieved in the chamber. To minimize the presence of residual impurities, the chamber was filled with high-purity nitrogen and a pumped again. The process was repeated three consecutive times. Borazine gas was then allowed to flow until the pressure was stabilized at $\sim 320 \mathrm{~Pa}$ (2.4 Torr). The substrate was heated to $500^{\circ} \mathrm{C}$ and the filament was heated to $2300^{\circ} \mathrm{C}$. In less than one minute, the substrate was covered with BN powder. About $85 \%$ of the borazine mass was converted into usable BN powder.
The theoretical optimum yield value is $92.5 \%$, considering the unavoidable evolution of hydrogen. Other losses are due to partial deposition on the interior surface of the CVD chamber. Various BN powder samples were isolated to analyze and compare their structure and composition. The samples were characterized by different techniques to determine their crystalline structure, morphology, and chemical composition: SEM (JEOL-models JSM-5800LV and JSM-6480LV), EDS (EDAX model Genesis 2000); XRD and XPS (Physical Electronics PHI 5600 ESCA system); FTIR (Bruker model TENSOR27/Helios ATR Diamond); SEM and EELS (LEO 922 OMEGA operated with an acceleration voltage of $200 \mathrm{kV}$ ). In order to perform TEM and EELS, the samples were placed on a copper grid covered with a thin carbon layer.

\section{Results and Discussion}

The TEM images (Figure 1) reveal that the BN powder consists of quasispherical nanoparticles, with diameters ranging between 20 and $50 \mathrm{~nm}$. These particles show a tendency to cluster into nanofibers of different lengths (between 80 and $500 \mathrm{~nm}$ ). The XRD diffractograms (not shown) contain a strong (002) peak and weak (101) and (102) peaks. They indicate that the crystalline structure of the $\mathrm{BN}$ powder is orthorhombic, hexagonal, or rhombohedral, or a combination of the three. The cross-sectional size of the particles observed in the TEM is consistent with the value of $27 \pm 6 \mathrm{~nm}$ obtained through the analysis of the XRD diffraction peak widths using Scherrer's equation [22]. Since the XRD diffractograms were taken on a relatively large sample volume, the value of $27 \pm 6 \mathrm{~nm}$ corresponds to the peak of the size distribution of the BN powder constituent particles.

EELS (Figure 2) provides information on the presence of boron and nitrogen. The peaks in the $198 \mathrm{eV}$ and $401 \mathrm{eV}$ regions are associated to the energy loss typical of these two elements, respectively. The structure close to the Kedge in the boron spectrum consists of a narrow $\pi^{*}$ peak at $191 \mathrm{eV}$, a broad $\sigma^{*}$ peak at $211 \mathrm{eV}$, and an additional peak at $\sim 197 \mathrm{eV}$ [23]. The presence of the $\pi^{*}$ peak indicates that the 

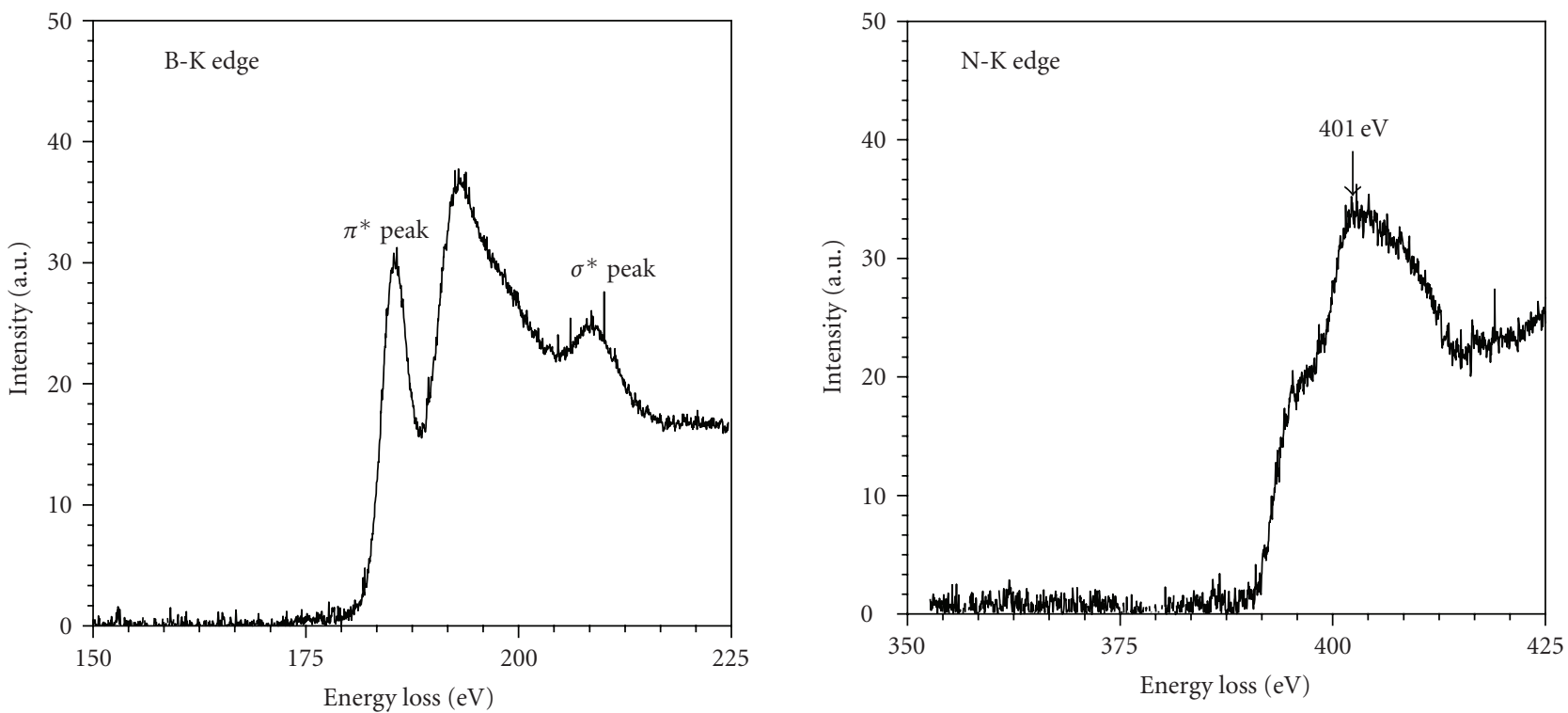

FIGURE 2: EELS spectra showing the bands corresponding to boron and nitrogen.
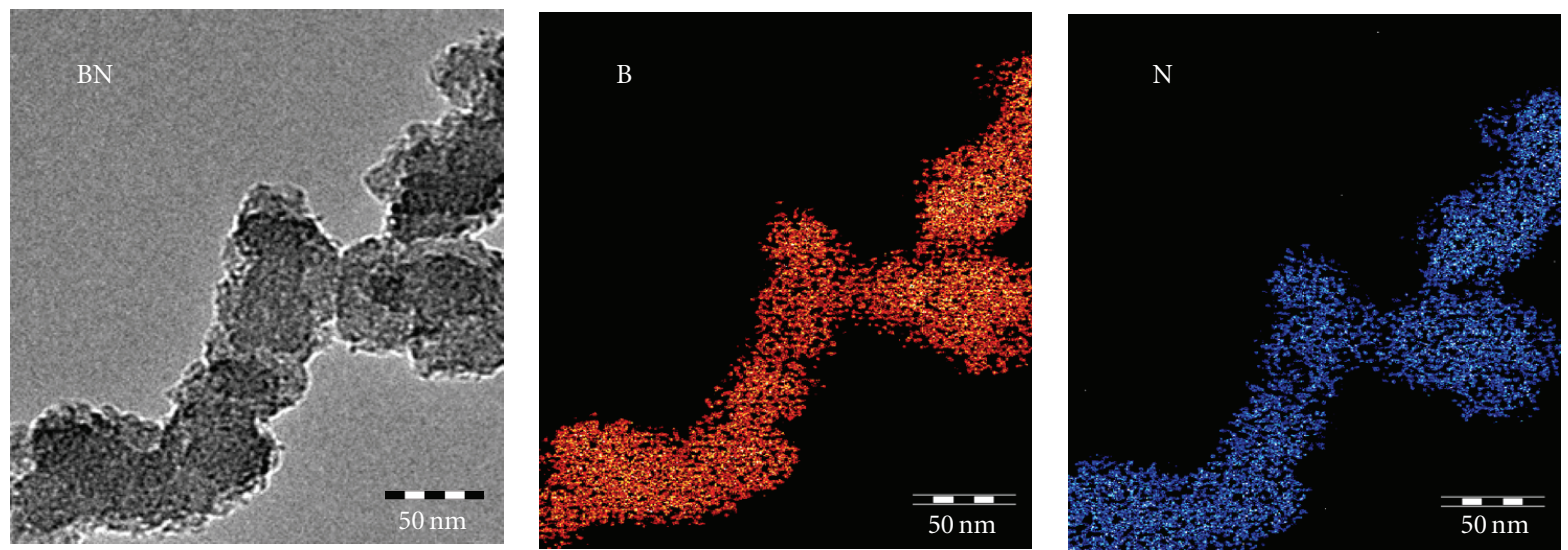

FIGURE 3: EELS elemental mapping of BN nanostructures. The red and blue colors correspond to the presence of boron and nitrogen, respectively.

$\mathrm{BN}$ nanoparticles have strong $\mathrm{sp}^{2}$ hybridization, analogous to carbon fullerenes. Subsequent elemental mapping using EELS (Figure 3 ) clearly shows that B (red color) and N (blue color) are uniformly distributed over the $\mathrm{BN}$ nanostructures. The presence of $\mathrm{B}$ and $\mathrm{N}$ according to the EELS mapping is homogenous and well overlapped throughout the BN nanostructures. The quantitative EELS analyses done throughout the $\mathrm{BN}$ nanostructures indicate that $\mathrm{B}$ and $\mathrm{N}$ are in $1: 1$ proportion within $2 \%$.

The infrared spectra of the BN nanostructures (Figure 4) show two prominent bands at $1373.2 \mathrm{~cm}^{-1}$ and $791.1 \mathrm{~cm}^{-1}$. Spectral deconvolution was used to identify the peaks that are merged together and determine their intensity and frequency, as shown in Figure 4. The deconvoluted spectra reveal that the wide band at $1373.2 \mathrm{~cm}^{-1}$ is composed of two peaks at $1380.2 \mathrm{~cm}^{-1}$ and $1477.2 \mathrm{~cm}^{-1}$; the band at $791.1 \mathrm{~cm}^{-1}$ is composed of two peaks at $787.1 \mathrm{~cm}^{-1}$ and
$803.9 \mathrm{~cm}^{-1}$; there is an additional weak band at $1103.1 \mathrm{~cm}^{-1}$. The peaks at $803.9 \mathrm{~cm}^{-1}, 1103.1 \mathrm{~cm}^{-1}$, and $1477.2 \mathrm{~cm}^{-1} \mathrm{can}$ be assigned to the e-BN phase, and those at 787.1 and $1380.2 \mathrm{~cm}^{-1}$ to the $\mathrm{rBN}$ [24] or h-BN $[25,26]$ phases. The e-BN is an allotropic form of boron nitride that has been reported to form by shock wave compression of h-BN powder using the explosion method [27]. So, it appears that HFCVD produces small amounts of the e-BN [24] phase, which coexist with h-BN and r-BN. It should be noted that there are no significant differences between the absorption coefficients of the different B-N phases [28].

The infrared results discussed above allow us to deduce that the BN nanostructures are mainly hexagonal or rhombohedral, or a combination of the two phases, which is consistent with the XRD results. Only small amounts of e$\mathrm{BN}$ appear to be present. The XRD results had also left open the possible existence of the orthorhombic phase, which is 


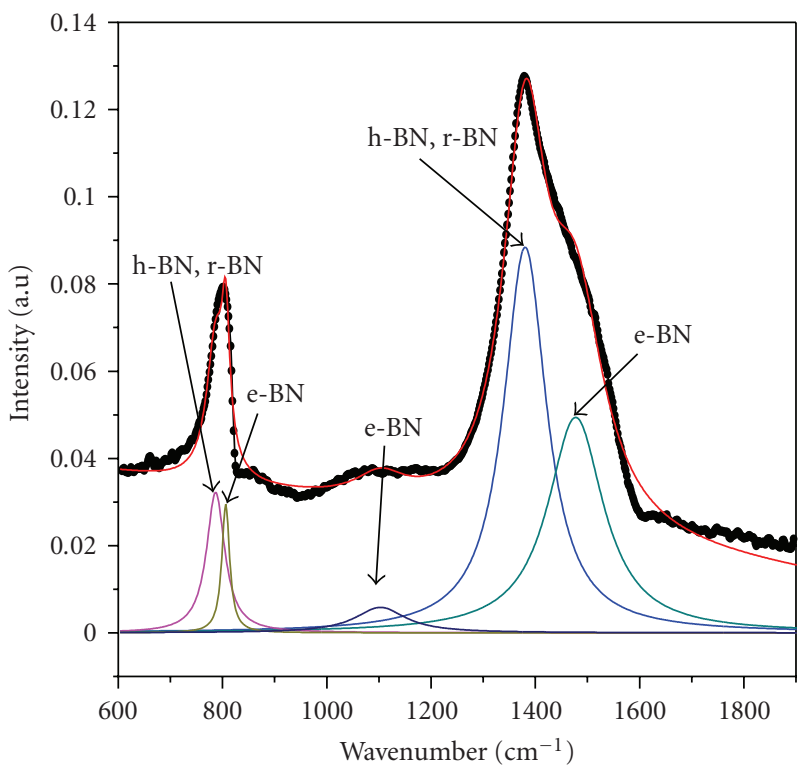

FIGURE 4: FTIR spectrum showing the typical bands of hexagonal and rombohedral BN structures.
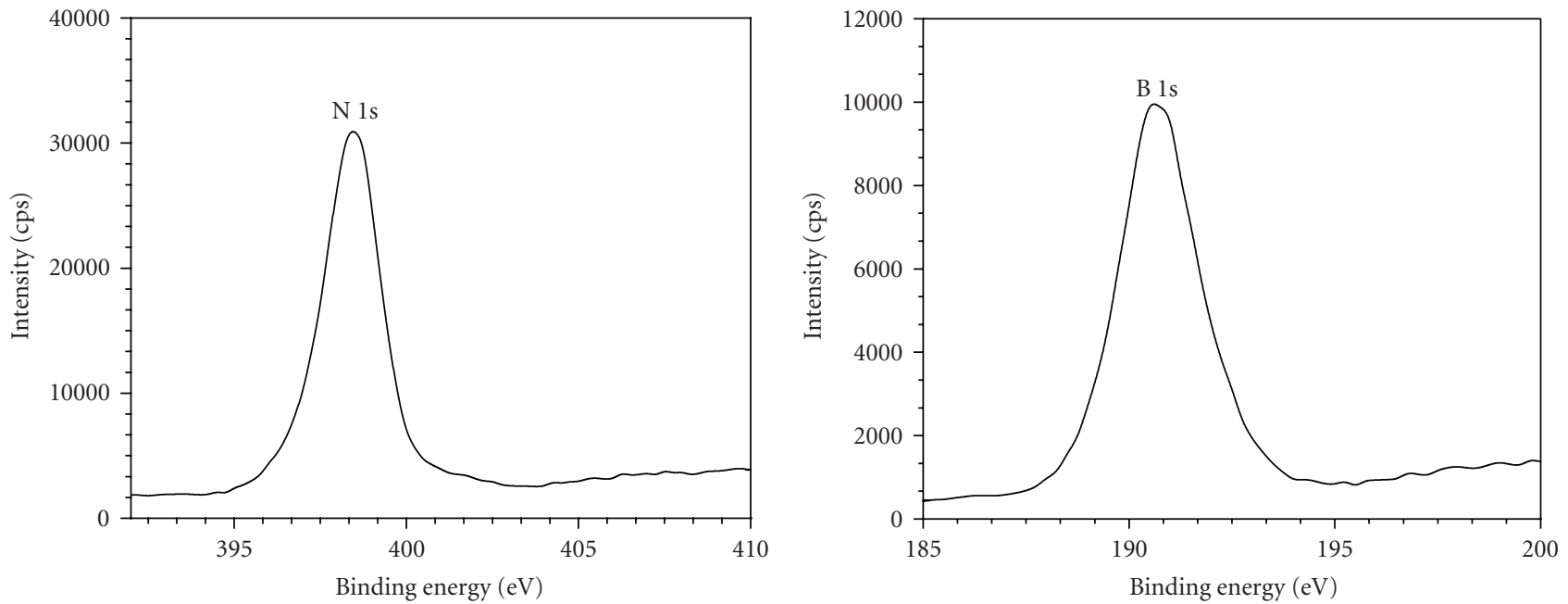

FIgURE 5: XPS spectrum in the N 1s $(398 \mathrm{eV})$ and B $1 \mathrm{~s}(190 \mathrm{eV})$ regions.

now discarded, since the peaks of that phase, which would appear in the vicinity of $1150 \mathrm{~cm}^{-1}$ [29], were not observed in the infrared spectra.

The XPS revealed the presence of nitrogen, boron, carbon, and oxygen with peaks at 398.76, 190.1, 284.85, and $534.87 \mathrm{eV}$ associated to the electronic levels of $\mathrm{N} \mathrm{1s,} \mathrm{B} \mathrm{1s,}$ $\mathrm{C} 1 \mathrm{~s}$, and $\mathrm{O} 1 \mathrm{~s}$, respectively. The peaks at $\mathrm{C} 1 \mathrm{~s}$ and $\mathrm{O} 1 \mathrm{~s}$ indicate the presence of oxygen and carbon impurities due the adsorption of $\mathrm{CO}_{2}, \mathrm{H}_{2} \mathrm{O}$, and $\mathrm{O}_{2}$ on the surface of the samples. The quantitative analysis of the $\mathrm{N} 1$ s peak, centered around $398.0 \mathrm{eV}$ [30] and of the peak corresponding to B 1 s centered around $190.7 \mathrm{eV}$ [31] (Figure 5), reveals that the atomic proportion of $\mathrm{B}$ to $\mathrm{N}$ is $1: 1( \pm 0.05)$, in agreement with the EELS analysis discussed above, indicating that the nanoparticles are essentially stoichiometric. Moreover, the energy position of the $\mathrm{B} 1 \mathrm{~s}$ band at $190.7 \mathrm{eV}$ indicates that the atomic surrounding of the boron atom consists of only nitrogen atoms [32], thus confirming the $1: 1$ stoichiometry of the product and the prevention of boron segregation by the method hereby described.

Based on the successful high-yield synthesis of stoichiometric BN nanostructures hereby reported, it can be speculated that the chemical mechanism consists of a series of borazine dehydrogenation reactions that result in the formation of a stoichiometric BN. The hot filament appears to induce the formation of excited borazine molecules, $\left(\mathrm{B}_{3} \mathrm{~N}_{3} \mathrm{H}_{6}\right)^{*}$, which undergo hydrogen dissociation that can be represented as follows: $\left(\mathrm{B}_{3} \mathrm{~N}_{3} \mathrm{H}_{6}\right)^{*} \rightarrow \mathrm{B}_{3} \mathrm{~N}_{3} \mathrm{H}_{5}+\mathrm{H}$. The presence of atomic hydrogen in the chemical vapor, in turn, triggers reactions that remove $\mathrm{H}$ from ground state borazine 
molecules while keeping the integrity of the $\mathrm{B}-\mathrm{N}$ bonds, as follows: $\mathrm{B}_{3} \mathrm{~N}_{3} \mathrm{H}_{6}+\mathrm{H} \rightarrow \mathrm{B}_{3} \mathrm{~N}_{3} \mathrm{H}_{5}+\mathrm{H}_{2}$. A cascade of analogous reactions leading to the formation of molecular hydrogen continues to occur at the expense of hydrogen atoms bonded to $\mathrm{BN}$ fragments. In this process, $\mathrm{BN}$ fragments segregate from the vapor phase and deposit on the substrate in the form of $\mathrm{BN}$ nanostructures. This proposed mechanism is consistent with the high yield of $\mathrm{BN}$, the absence of boron segregation or nitrogen deficiency in the product, and the sharp increase in total pressure that occurs at the point when the filament is heated above $2000^{\circ} \mathrm{C}$.

\section{Conclusion}

The high-yield synthesis of stoichiometric BN nanostructures using borazine gas as chemical precursor and the HFCVD technique has been demonstrated. The structure, morphology, and chemical composition of these nanostructures were studied. The $\mathrm{BN}$ nanostructures include quasispherical nanoparticles with sizes ranging between 20 and 50 nanometers and nanofibers of the same diameter that measure from 80 to 500 nanometers in length. There is no evidence of elemental $\mathrm{B}$ phase segregation or $\mathrm{N}$ deficiency. The comprehensive characterization study done indicates that all of the powder material obtained is stoichiometric BN mainly in the hexagonal and rhombohedral phases. Therefore, this study has resulted in the development of a new method to achieve the high-yield synthesis of stoichiometric $\mathrm{BN}$ nanostructures that can be employed to enhance the strength of structural materials of industrial applications.

\section{Acknowledgments}

The authors wish to acknowledge the financial support of NASA URC (NNX08BA48A) and PR NASA EPSCoR RID (NNX07AO30A). They also thank Josué Ortiz (SEM), Oscar Resto and Javier Ávalos (MET), Neiza Hernández (FTIR), and Esteban Fachini (XPS). Piazza thanks the Secretary of State of Higher Education, Science and Technology (SEESCYT) of the Dominican Republic (2007 and 2008 FONDOCYT program) and the Pontificia Universidad Católica Madre y Maestra (2007-2008 Grants for Research).

\section{References}

[1] D. Golberg, A. Rode, Y. Bando, M. Mitome, E. Gamaly, and B. Luther-Davies, "Boron nitride nanostructures formed by ultra-high-repetition rate laser ablation," Diamond and Related Materials, vol. 12, no. 8, pp. 1269-1274, 2003.

[2] Z. Karim, D. C. Cameron, M. J. Murphy, J. Hashmi, and E. Masme, "Vapour deposited boron nitride thin films: a review," in Materials and Processes/European Engineering Research and Technology Transfer Congress (Eurotech Direct '91), pp. 181189, Birmingham, UK, July 1991.

[3] M.-F. Ng and R. Q. Zhang, "Optical spectra of single-walled boron nitride nanotubes," Physical Review B, vol. 69, no. 11, Article ID 1154176, 6 pages, 2004.

[4] G. G. Fuentes, E. Borowiak-Palen, T. Pichler, et al., "Electronic structure of multiwall boron nitride nanotubes," Physical Review B, vol. 67, no. 3, Article ID 035429, 6 pages, 2003.
[5] W.-Q. Han, W. Mickelson, J. Cumings, and A. Zettl, "Transformation of BxCyNz nanotubes to pure BN nanotubes," Applied Physics Letters, vol. 81, no. 6, pp. 1110-1112, 2002.

[6] L. A. Chernozatonskii, E. G. Gal'pern, I. V. Stankevich, and Y. K. Shimkus, "Nanotube C-BN heterostructures: electronic properties," Carbon, vol. 37, no. 1, pp. 117-121, 1999.

[7] D. Golberg, Y. Bando, M. Mitome, et al., "Nanocomposites: synthesis and elemental mapping of aligned B-C-N nanotubes," Chemical Physics Letters, vol. 360, no. 1-2, pp. 1-7, 2002.

[8] A. Bath, P. J. van der Put, J. Schoonman, and B. Lepley, "Study of boron nitride gate insulators grown by low temperature plasma enhanced chemical vapor deposition on InP," Applied Surface Science, vol. 39, no. 1-4, pp. 135-140, 1989.

[9] H. Miyamoto, M. Hirose, and Y. Osaka, "Structural and electronic characterization of discharge-produced boron nitride," Japanese Journal of Applied Physics, vol. 22, no. 22, pp. L216L218, 1983.

[10] S. Iijima, "Helical microtubules of graphitic carbon," Nature, vol. 354, no. 6348, pp. 56-58, 1991.

[11] O. R. Lourie, C. R. Jones, B. M. Bartlett, P. C. Gibbons, R. S. Ruoff, and W. E. Buhro, "CVD growth of boron nitride nanotubes," Chemistry of Materials, vol. 12, no. 7, pp. 1808$1810,2000$.

[12] L.-X. Lin, Y. Zheng, Y. Zheng, and K.-M. Wei, "Facile synthesis of hexagonal boron nitride fibers and flowers," Materials Letters, vol. 61, no. 8-9, pp. 1735-1737, 2007.

[13] W. Mickelson, S. Aloni, W.-Q. Han, J. Cumings, and A. Zettl, "Packing $\mathrm{C}_{60}$ in boron nitride nanotubes," Science, vol. 300, no. 5618, pp. 467-469, 2003.

[14] T. Oku, M. Kuno, H. Kitahara, and I. Narita, "Formation, atomic structures and properties of boron nitride and carbon nanocage fullerene materials," International Journal of Inorganic Materials, vol. 3, no. 7, pp. 597-612, 2001.

[15] F. L. Deepak, C. P. Vinod, K. Mukhopadhyay, A. Govindaraj, and C. N. R. Rao, "Boron nitride nanotubes and nanowires," Chemical Physics Letters, vol. 353, no. 5-6, pp. 345-352, 2002.

[16] T. Oku, K. Hiraga, T. Matsuda, T. Hirai, and M. Hirabayashi, "Formation and structures of multiply-twinned nanoparticles with fivefold symmetry in chemical vapor deposited boron nitride," Diamond and Related Materials, vol. 12, no. 10-11, pp. 1918-1926, 2003.

[17] A. Essafti, "Efecto de la temperatura de deposición en las características estructurales y ópticas de películas delgadas de nitruro de boro obtenidas por CVD," Boletín de la Sociedad Española de Cerámica y Vidrio, vol. 46, no. 3, pp. 127-130, 2007.

[18] R. S. Lee, J. Gavillet, M. Lamy de la Chapelle, et al., "Catalystfree synthesis of boron nitride single-wall nanotubes with a preferred zig-zag configuration," Physical Review B, vol. 64, no. 12, Article ID 121408, 4 pages, 2001.

[19] J. J. Velázquez-Salazar, E. Muñoz-Sandoval, J. M. RomoHerrera, et al., "Synthesis and state of art characterization of BN bamboo-like nanotubes: evidence of a root growth mechanism catalyzed by Fe," Chemical Physics Letters, vol. 416, no. 4-6, pp. 342-348, 2005.

[20] S. Hirano, T. Yogo, S. Asada, and S. Naka, "Synthesis of amorphous boron nitride by pressure pyrolysis of borazine," Journal of the American Ceramic Society, vol. 72, no. 1, pp. 6670, 1989.

[21] S. Shanfield and R. Wolfson, "Ion beam synthesis of cubic boron nitride," Journal of Vacuum Science and Technology A, vol. 1, no. 2, pp. 323-325, 1982. 
[22] I. V. Alexandrov and N. A. Enikeev, "X-ray analysis and computer simulation for grain size determination in nanostructured materials," Materials Science and Engineering A, vol. 286, no. 1, pp. 110-114, 2000.

[23] D. R. McKenzie, W. D. McFall, W. G. Sainty, C. A. Davis, and R. E. Collins, "Compressive stress induced formation of cubic boron nitride," Diamond and Related Materials, vol. 2, no. 5-7, pp. 970-976, 1993.

[24] L. Yu, B. Gao, Z. Chen, et al., "In situ FTIR investigation on phase transformations in BN nanoparticles," Chinese Science Bulletin, vol. 50, no. 24, pp. 2827-2831, 2005.

[25] L. Chen, Y. Gu, Z. Li, Y. Qian, Z. Yang, and J. Ma, "Low-temperature synthesis and benzene-thermal growth of nanocrystalline boron nitride," Journal of Crystal Growth, vol. 273, no. 3-4, pp. 646-650, 2005.

[26] W. X. Pan, L. Vandenbulcke, J. P. Rouan, P. Baillif, and R. Erre, "Characterization of boron nitride films deposited from $\mathrm{BCI}_{3}$ $\mathrm{NH}_{3}-\mathrm{H}_{2}$ mixtures in chemical vapour infiltration conditions," Journal of Materials Science, vol. 29, no. 6, pp. 1417-1435, 1994.

[27] A. Olszyna, J. Konwerska-Hrabowska, and M. Lisicki, "Molecular structure of E-BN," Diamond and Related Materials, vol. 6, no. 5-7, pp. 617-620, 1997.

[28] P. B. Mirkarimi, K. F. McCarty, and D. L. Medlin, "Review of advances in cubic boron nitride film synthesis," Materials Science and Engineering R, vol. 21, no. 2, pp. 47-100, 1997.

[29] M.-Y. Yu, K. Li, D.-L. Cui, S.-Y. Dong, Q.-L. Wang, and M.H. Jiang, "Effects of temperature raising speed on the growth of BN crystals in hydrothermal solutions," Chinese Journal of Chemistry, vol. 22, no. 6, pp. 528-532, 2004.

[30] C. Gomez-Aleixandre, A. Essafti, and J. M. Albella, "Kinetic Study of the diborane/methylamine reaction: composition and structure of C-B-N films," The Journal of Physical Chemistry B, vol. 104, no. 18, pp. 4397-4402, 2000.

[31] A. Essafti, C. Gomez-Aleixandre, J. L. G. Fierro, M. Fernández, and J. M. Albella, "Chemical vapor deposition synthesis and characterization of co-deposited silicon-nitrogen-boron materials," Journal of Materials Research, vol. 11, no. 10, pp. 2565-2574, 1996.

[32] C. Guimon, D. Gonbeau, G. Pfister-Guillouzo, et al., "XPS study of $\mathrm{BN}$ thin films deposited by $\mathrm{CVD}$ on $\mathrm{SiC}$ plane substrates," Surface and Interface Analysis, vol. 16, no. 1-12, pp. 440-445, 1990. 

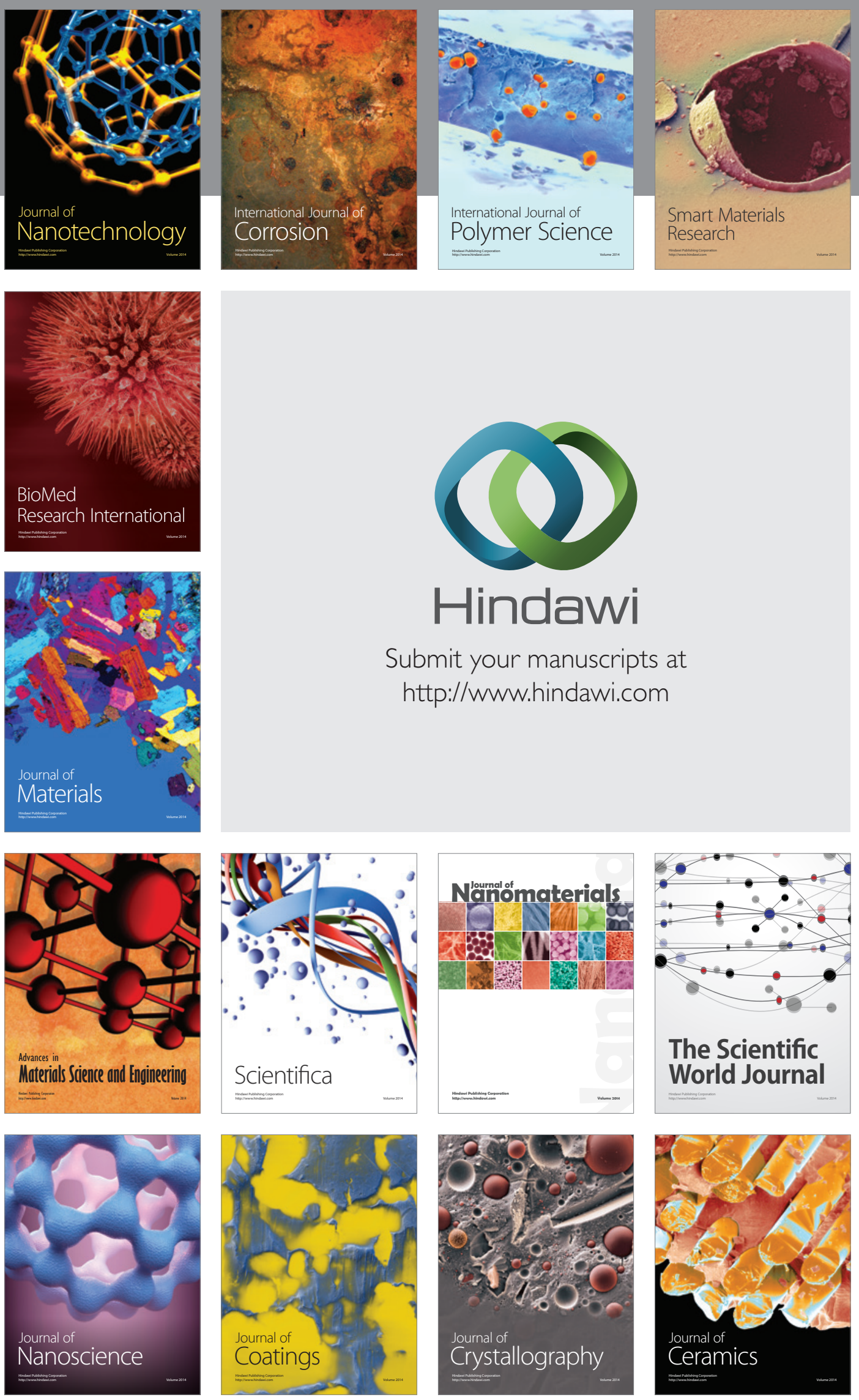

The Scientific World Journal

Submit your manuscripts at

http://www.hindawi.com

\section{World Journal}

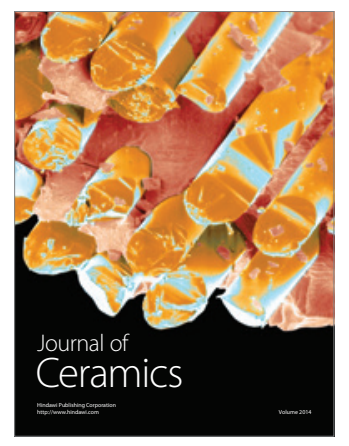

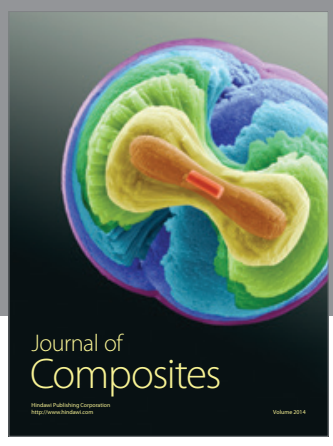
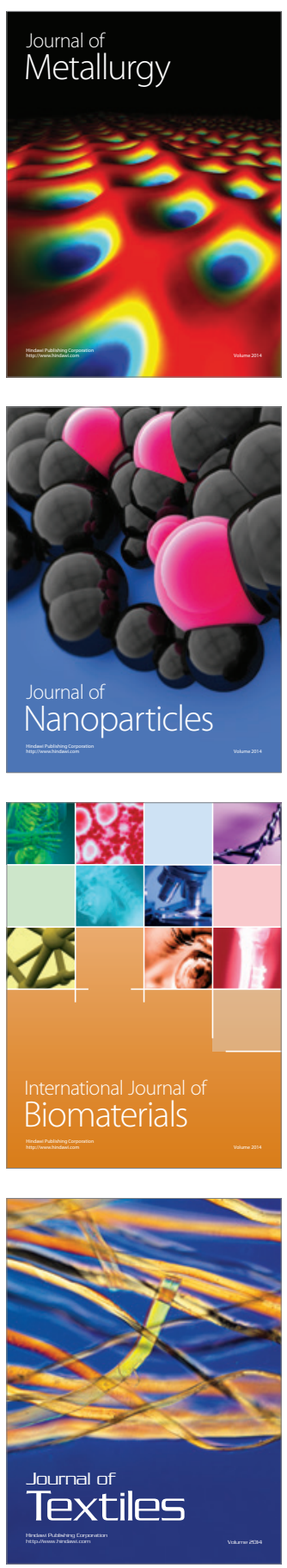